But " intzence of this article, the petolishor or recipient acknowledges the U.S. Government's right to retain a nonexclusice, royalty-free license in and to any copyright covering the article.

\section{COLF $-330406--34$}

DE83 012067
This report was prepared as an account of work sponsored by an agency of the United States Government. Neither the United States Government nor any agency thereof, nor any of their employees, makes any warranty, express or implied, or assumes any legal liability or responsibility for the accuracy, completeness, or usefulness of any information, apparatus, product, or process disclosed, or represents that its use would not infringe privately owned rights. Reference herein to any specific commercial product, process, or service by trade name, trademark, manufacturer, or otherwise does not necessarily constitute or imply its endorsement, recommendation, or favoring by the United States Government or any agency thereof. The views and opinions of authors expressed herein do not necessarily state or reflent those of the United States Government or any agency thereof.

\title{
RADIO-FREQUENCY ENERGY IN FUSION POWER GENERATION
}

$$
\text { CCNF-830406--34 }
$$

John Q. Lawson Princeton Plasma Physics
Laboratory

Princeton, NJ 08540

(FTS) $340-2128$
W. R. Becraft

General Electrfc Company Schenectady, $\mathbb{N Y} 12345$

\author{
D. J. Hoffman \\ Oak Rldge National Laboratory ${ }^{\alpha}$ \\ P. 0. Box $X$ \\ Oak Ridge, TN 37830 \\ (615) $574-1115$
}

\section{ABSTKACT}

The history of radio-frequency ( $r f$ ) energy in fusion experiments is reviewed, and the status of current efiorts is described. Potential applications to tasks othez than plasma heattng are described, as are the research and development needs of rf energy technology.

\section{INTRODUCTION}

Early studies of controlled thermonuclear Eusion, around 1953, proposed methods of heating that generally included radio-frequency ( $I F$ ) power in the very low frequency (VLF) region. Such systems as the "B-Oscillator" and the "Test MOPA," for use in magnetic pumping, operated in a frequency range of $100-200 \mathrm{kHz}$. In 1957, T. Stix of Princeton University proposed and demonstrated that a high frequency (HF) rf system would couple energy efficiently to the plasma at the ion cyclotron resonance frequency. Experimental results conducted with $\mathrm{rf}$ source capabilities of $1 \mathrm{MW}$ on the $\mathrm{B}-65$ at $12 \mathrm{MHz}$ and the $\mathrm{B}-66$ at $16 \mathrm{MHz}$ indicated that $\mathrm{rf}$ energy was a strong candidate for reactor heating. Problems of confinement and impurity influx plagued plasma $\Xi$ tudies for the next decade. These anomalies limited rf heating studies to power levels of a few hundred kilowats, even though significant developments were made in megawat $r \bar{x}$ power sources up to and including the very high frequency (VHF) range.

At fusion laboratorles the world over, starting about 1975, major commitments were made to heat plasmas by means of ion cyclotron resonance heating (ICRH), electron cyclotron resonance heating (ECRH), and nybrid schemes with high power if sources. Success in varying degrees has been achieved. As experimencs and theoretical calculacion continued, other roles for $r f$ hearing were devised. Each method of hearing and/or plasma control requires a particular part of the spectrum for proper operation.

Operated by Union Carbide Corporation under contract $\$-7405$-eng- 26 with the U.S. Department of Energy.
The ion cyclotron range of frequenctes (ICRF) lies in that portion of the rf spectrum that includes such servicas as the AM broadcast band [medium frequency (MF), 300-3000 kHz], the international communications and broadcast band (HF, 3-30 MHz) and the VHF television/FM broadcasting band (VHF, 30-300 $\mathrm{MHz}$ ). Many years of development and operation in these frequency ranges by comerclal and government Interests enabled the fusion program to move to relatively hIgh power levels without a major equipment development program. However, this fortuttous ctrcumstance is no longer applicable, and much research and development in component parts, such as racuum tubes, will be required to construct $r f$ systems to meet the needs of present and future machines.

The primary role that ICRF heating will play in the tokamak reactor will be in heating the plasma at the fundamental and second harmonic regimes. For the first fusion reactor, this mode of heating will require rf power levels in the 100-iT range. At this time, existing rf systems for plasma mactines are capable of only $5 \mathrm{MW}$. In addition to resonance heating, the ICRF power sources will be used for plasma current drive. This scheme is particularly practical in large reactor vessels, where physical spacings will allow for arrays of waveguide launchers in a fast wave configuration.

The lower hybrid range of frequencies (LHRF) covers that portion of the if spectrum which is used for ultrahigh frequency (UHF) television and microwave heating (UHF, 300-3000 Miz). The primary role envisioned for LHRF is "current drive." The $r f$ energy is used to provide excitation to electrons in a unidirectional mode so that a net current flow in the plasma will allow continuous operation of the tokamak reactor. LHRF may also be used for plasma heating. However, further investigation is required to prove that this method of heating is practical. Power levels of $10-50 \mathrm{MW}$ are envisioned for current drfve of a full-size reactor. Post-World War II development of high power gridded tubes and $20.5-\mathrm{MW}$ klystron ampi1fiers has provided the means to satisfy power 
requirements of existing experimental machines up to the size of the Tokamak Fusion Test Reactor (TFTR).

Experfmentation in the heating of plasmas by excication of electrons at their resonant frequancy has been under way since 1960 at Oak RIdge National Laboratory (ORNL). With the developmeat of the gyrotron oscillator in Russia; the heating mode (ECRH) of the electron cyclotron range of frequencies (ECRF) has become an additional factor in the role that if energy will play in fusion power generation.

The low frequency end of the ECRF extends from 10 to $30 \mathrm{GHz}$; the high frequency end, from 30 to $300 \mathrm{GHz}$. This band of frequencles has been used mainly for radar, comonications, and radio astronomy with systems in which average power levels are quite low. Much development work is still under way for high power sources that operate in the range from 60 to $300 \mathrm{GHz}$. To date, levels of several hundred kllowates represent the state of the art. Tokamaks, as presently concelved, will have field strengths that produce electron resonances between 30 and $200 \mathrm{GHz}$. The major roles now envisioned for ECRF are plasma start-up and profile control of the plasma by means of selective heating.

To accomplish cost-effective rf operation of a reactor, tube and component development beyond the present state of the art will be required. Development of new techniques to raise the operating efficiency of whatever sources are ultimately used will also be required to minimize reactor operating costs.

\section{HISIORICAL BACKGROUND}

According to a history of Project Matterhorn, I Lyman Spitzer, Jr., chairman of the Princeton University astronomy department; John Wheeler, a Princeton physicist; and J. Tuck of Los Alamos Scientific Laboratory met at the headquarters of the Atomlc Energy Commisston on May 11, 1951, to discuss a possible metrod to confine a thermonuclear plasma. In the same history, it is noted that in March 1953 a paper by Spiczer and Witten first addressed the problem of plasma heating, and a method called "induction heating" was chosen to heat the first fusion devices. Another method of ionization and heating, which is still used, was devised by J. M. Berger and E. A. Frieman, also in 1953, and described in a paper entitled "On the Pulse Method of Ionization and Heating of a Plasma." 2 A high voltage electric field, magnetically coupled into the confinement vessel, results in the iontzation of a controlled amount of hydrogen or deuterium and causes ionization of the gas. This is followed by a unidirectional pulse of current coupled into the iontaed gas. The plasma is then heated ohmically to a cemperature between 1.0 and 30 million kelvin, where the resistance of the plasma is so low that no further heating occurs. Since this temperature ( $1 \mathrm{keV}=10$ million kelvin) was well below the 100 million kelvin required for reactor operation, a number of auxiliary hearing methods described by Spitzer and Witten's survey were considered. Varlous experiments to heat by magnetic pumping ${ }^{3}$ on the $B-2$ stellarator were made but proved disappointing in that they did not reach their goal.

The real beginning in the use of $r f$ energy for fusion machines came from results of the successful ICRH on the B-65 and B- 66 machines, a direct result of basic ideas put forth by T. Stix in a paper published in the Physical Review, "Oscillations of a Cylindrical Plasma." This highly successful idea has been used at Princeton on the Model C Stellarator, the ST tokamak, the Adlabatic Toroidal Compressor (ATC), and the Prfnceton Large Torus (PLT). Proposals are being developed to install ICRH on the largest U.S. fuston machine, TFTR. During the period from 1960 to 1970, much of the physics of ICRH heating was developed by use of a $25-\mathrm{MHz}$, 4- $\mathrm{HW}$, short pulse generator. This unit is still in use, having been most recently modified to a $30-\mathrm{MHz}$, 2-MW, long pulse generator. The period from 1970 to 1980 saw great strides in heating, first on ST and then on PLT. Joel Hosea proposed a half-turn rf coil as the coupler of energy to the plasma. Despite the fact that the operating frequency of the high power generator was too low for good high field machine operation, a doubling of ion temperature was achieved on the SI machine. After another successful ICRh run on ATC, in which the rf power in joules was increased 10 -fold over that of the ST machine, a decision was made by Princeton to continue ICRH experiments on PLT, and two high power (55-MHz), 2.5-MW, long pulse generators were built and later modified to $42 \mathrm{MHz}$. These generators and the $25-\mathrm{MHz}$ generator have over the past four years raised the ion temperature to $2.3 \mathrm{keV}$ above the $0.5-\mathrm{keV}$ ohmic temperature. 5 It is at this point that the technological problems are beginning to loom as large as the physics problems.

In the early 1960s, experiments in lower hybrid heating were trled on the B-3 machine. A $25-\mathrm{kW}$ television transmitter was coupled to the plasma through single-turn coils at $500 \mathrm{MHz}$. Plasmas were produced in which the energy penetrated to the center of the plasma. However, the lower hybrid heating phenomenon was not observed, and as Dr. Tanner points out most succinctly in his history, the "subject of lower hybrid heating was put to one side, for a while." In 1972, W. Hooke and S. Bernabei restarted investigation of the lower hybrid phenomenon. Shortly thereafter, they were joined by $R$. Notley, who began experiments on coupling by phased arrays based on studies by Lallia and Brambilla in Grenoble. In 1976, four high power klystrons ( $55 \mathrm{~kW}$ at $800 \mathrm{MHz}$ ) and a 4-waveguide phase array were installed to couple lower hybrid energy into the ATC machine. The results, again, were disappointing, not from 
the coupling standpoint, which was excellent, but from the apparent contradiction in data. Unfortunately, the tests were concluded before the conflict in data could be resolved because the ATC area had been allocated for the new Pololdal Divertor Experiment (PDX) machine. The lower hybrld physiclsts and engineers were undaunted, however, and upgraded the if system to $\mathrm{six}$ generators, each with a $200 \mathrm{~kW}$ ourput and long pulse capability, for use on the PLT machine to resolve once and for all the physics of lower hybrid heating. In addition, this if system was used to determine if this frequency range could be used to drive an unidirectional current in the plasma. At this time, the jury is still out on lower hybrid heating. However, great strides have been made in driving a current in PLT. 6 The caveat on the currens drive is that at $800-\mathrm{MHz}$ excitation there is a density limit at about $7 \times 10^{12} \mathrm{~cm}^{-3}$, which is tos low for a working reactor.

high power, lower hybrld experiments have been performed at other laboratories, including those at the Massachusetts Institute of Technology (MIT) and General Atomic Company (GA) in the United States; at the Japan Atomic Energy Research Institute (JAERI), Nagoya University, and Kyoto Universicy in Japan; and in France, Italy, and the Federal Republic of Germany. Each of these groups has contributed to the physics and technological store of knowledge.?

In the years since 1960, there has been a consistent effort by Dandl, England, and others to study and define the role that ECRH would have in a reactor. Work was done first in simple mirror machines ${ }^{8}$ and later in the ELMO Bunpy Torus (EBT), a closed mirror machine. ${ }^{3}$ In this same time period, the Russians developed a high power millimeter wave oscillator or "gyrotron" and were heacing tokamaks with ECRH. Varian Associates, under subcontract to ORNL, started a study of gyroklystron (gyrotron) devices and was confident that tubes with $200-\mathrm{kW}$ output power up to $120 \mathrm{GHz}$ in frequency could be built. This program, urider the guidance of Oak Ridge, has produced reliable $28-$ and $50-\mathrm{GHz}$ tubes at the $200-\mathrm{kW}$ output level.

\section{POTENTIAL, USES FOR RF ENERGY}

The history of $\mathrm{rf}$ energy in fusion exper 1 ments indicates that the majority of work done, to this point, has been directed toward bulk heating of the plesma componezts. As we move closer to a functioning reactor, rf energy will be a strong contender for maig ancillary tasks as well. The roster of these tasks shown in Table 1 is by no means complete, since we do not know all the problems that will be encountered in a reactor. This last statement may seem presumptuous, but if one considers the following facts, there is surely a good basis for believing that if energy application cen solve many reactor problems.
Table 1. RF energy tasks

A. Heating

1. Ions (resonant coupling)

2. Electrons (resonant coupling)

3. Electrons (wave coupling)

B. Current drive

C. Start-up

D. Profile control

E. Particle control

1. Heavy impurities

2. Light impurities

First, the lonlzed fuel particles in a plasma, both lons and electrons, when confined in a magnetic field, have gyrofrequencies identical to the frequencies of If generators that can be bullt and used to drive these resonances. Second, if energy can be 1mparted to the lontzed particles in different directions simply by phasing the coupling devices. Third, the condult by which energy is fed into the fusion machine can be bent and shielded so that high energy neutral particles produced by the machine do not enter the heating source but can be captured by the heat exchange blankets that surround the machine. Fourth, rf generators can be operated at frequencies that are the gyrofrequencies of impurities in the plasma. By ingentous coupler design, one might be able to remove or divert the impurities. Fifth, if energy is in the form of electromagnetic waves when it leaves the ancenna or coupling device; this energy can be made to travel around a closed device to deposit energy in the center of the plasma.

The most serious problem we face at this time is to declde which tasks to concentrate on and which frequency will give the optimum results.

\section{BASIC RF PARAMETERS}

There are only a few plasma equations with which the average if engineer must be conversant. However, some of the relationships of frequency to machine conditions will clarify the magnitude of tine scope of probable uses of $r f$ in fusion machines. The equations for ion $\left(f_{c i}\right)$, electron $\left(f_{c e}\right)$, and hyorid $\left(f_{1 h}\right)$ gyrofrequency and ton $\left(f_{p i}\right.$ ) and electron ( $\left.f_{p e}\right)$ plasma irequency are as follows:

$$
\begin{aligned}
& f_{C i}=\omega_{C i} / 2 \pi \times 1.52 \times 10^{3} \mathrm{Z \mu}^{-1} \cdot \mathrm{B}, \\
& \mathrm{f}_{\mathrm{Ce}}=\mathrm{\omega}_{\mathrm{C} e} / 2 \pi=2.80 \times 10^{5} \mathrm{~B},
\end{aligned}
$$




$$
\begin{aligned}
& f_{L H}^{2}=\frac{f_{p I}^{2}}{1+\left(f_{p e}^{2} / f_{c e}^{2}\right)}, \frac{f_{p e}^{2}}{f_{c e}^{2}}=\frac{f_{p i}^{2}}{f_{c I} f_{c e}}, \\
& f_{p i}=\omega_{p I} / 2 \pi=2.10 \times 10^{2} Z_{\mu^{-1} / 2 \eta_{i}^{-1 / 2},} \\
& f_{p e}=\omega_{p e} / 2 \pi=8.98 \times 10^{3} \eta_{e}^{1 / 2},
\end{aligned}
$$

where $Z$ is the charge state, $\mu$ is the ratio of the ion mass to the pruton mass, $B$ is field strength (in gauss), and $\eta$ is density.

If we take a reasonable range of magnetic field strengths that might occur in a fusion reactor, we find that curves may be drawn to show the approximate operating frequenctes that must be provided for the test and final reactors. Flgure 1 shows a plot of such calculations for

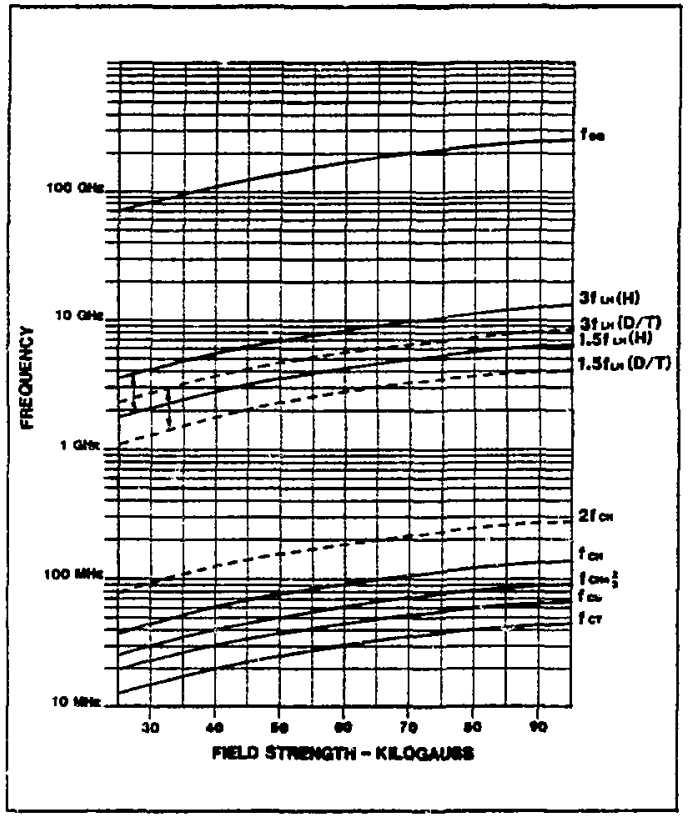

Fig. 1. Frequency variation with fleld strength.

hydrogen, helium, deuterium, and tritfum. There are some unique occurrences on this graph that should be noted. At a given field strength, the second harmonic of deutertum ions is the same as the fundamental frequency of hydrogen ions, and the second harmonic of tritium ions is the same as the fundamental frequency of helium ions. It should also be noted that $f_{c e}$ in any HF or even MF machine is extremely high [in the superhigh frequency (SHF) range], and wuch work needs to be done in this area. The curves for lower bybrid heating and current drive are based on plasmas with an equal electron plasma frequency and gyrofrequency, $\omega_{p e}=\omega_{c e} \cdot$ The curves of $1.5 f_{1 h}$ for lower hybrid hearing and $3 f_{1 h}$ for lower hybrid current drive are good approximations. 10 The largest U.S. tolkamak, TFTR, would normelly operate at $50 \mathrm{kG}$ and would require an ton cyclotron generator that operates from 25 to $150 \mathrm{MHz}$, a lawer hybrid generator that operates from 2.45 to $7.0 \mathrm{GHz}$, and an ECRH generator that operates at about $140 \mathrm{GHz}$.

That is the most straightforward portion of the basic rf parameters. The more difficult portion in the rase of heating (or plasma current value of some magnitude in the case of current drive) is the determination of power requirements. Some approximations of the various conditions are given below. These should be used with great caution since there are no adequate experimental data or schemes to opt1mize elther coupling mechanisms or modes.

\section{EQUIPMENT TO ACCOMPLISH RF TASKS}

In thinking about rf energy in a "global" sense, whether it be a radio transmitter, a radar unit, a microwave heater, or a fuston generator, there are some basic components and some special components. Fortunately for the fusion community, there are engineers who can move from one discipline to another, and if we can interest one or two universities in teaching the fine art of electron tube design and high power circuit computation and design, there w1ll be a supply of engineers to build the high power rf systems shown in Fig. 2.

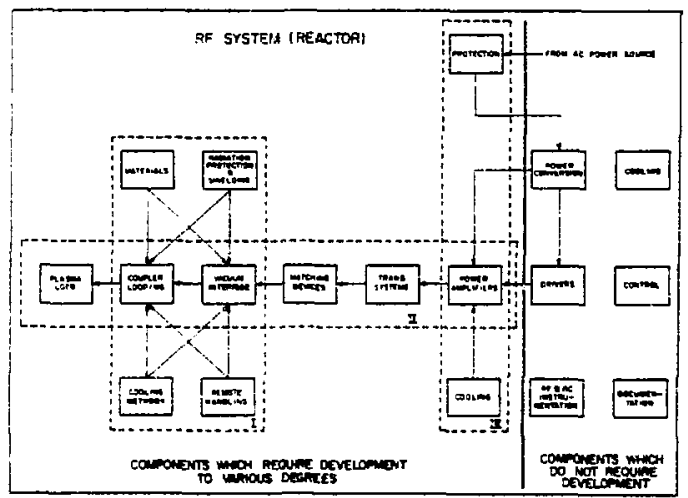

FIg. 2. High-power if system for reactor.

With the exception of the special reactor Eacets in block $I$, the present-day rf generators fit the diagram in FIg. 1. In the ICRF range, we are able to approach $2.5 \mathrm{MW}$ out of a single tube; in the lower hybrid range, $500 \mathrm{~kW}$ out of a single tube; and in the ECRH range, $200 \mathrm{~kW}$ out 
of a single tube. These power levels are very impressive. However, for a reactor this would mean 100 unit amplifier systems for ICRF, 20 to 40 unit amplifier systems for lower hybrid, and 100 unit amplifler systems for ECRH. Such a ;arge number of unit systems would not be cost-effective in terms of space, manufacturing, or reliability because of the sheer number of components. One must compromise between what can be done with present-day components and the production of a costeffective, reliable system. In order to make ihis compromise and to develop components to achieve the compromise, we should examine each block of Fig. 2 in some detall for the three basic systems: ICRF, LHRF, and ECRF.

Two of the items in block I, the vacuum vessel interface and the coupler, are part of the $r f$ power flow to the plasma load. These items must therefore be capable of handling the power, in terms of the voltage and current and of the frequency in the ICRF range. A typical example for a near-reactor-size machine 11 shows that a ridged waveguide could support up to 48 MW into a matched load and that it is realistic to think of $10 \mathrm{MW}$ per waveguide with two guides stacked one above the other so that $>100 \mathrm{NW}$ could be transferred into a machine in the manner shown in Fig. 3. The next block in the path toward the power amplifiers is the vacuum interface, which, because it is made of ceramic and metal, is more susceptible to radiation damage than the all-metal coupler. Therefore, the vacuum seals must be placed in the coaxial feed lines behind radiation shields. The development of the vacuum interface will depend to a large extent on the uniformity of thi plasma load in a reactor or on the varlation in the standing wave ratio caused by the plasma load changes during the heating cycle.

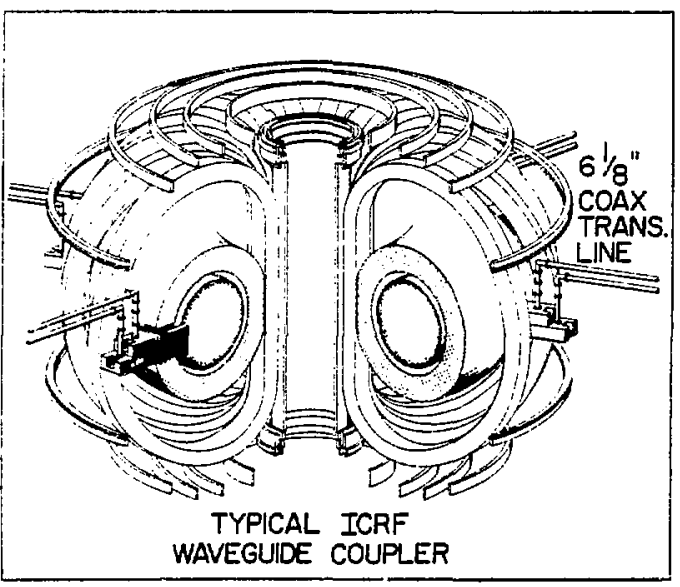

Fig. 3
The other parts of block I have to do mainly with reactor performance and design. Close cooperation between machtne designers, rf physicists, and engineers will be required. Materials for the couplers and racuum interfaces wlll be of the same material as the first wall of the machine, with some type of high conductivity plating in high current areas to minimize if source power losses. Cooling and remote handling will also follow the design of the machine, with special consideration given to areas that have if current interfaces with the sources.

As we contintie toward the source of if energy, matching devices will be required to minimize VSWR losses and maximize the amount of power that can be carried over a transmission 1ine. These units should not be too difficult to build and should not require tuning in a reactor. The transmission system Eor ICRF will most likely be coaxial ines, the power handling capability of which is well documented. The design in Fig. 3 shows $10 \mathrm{MW}$ in 6.125-in. copper lines. 13 This is accomplished by pressurizing the line at 20 psig with $\mathrm{SF}_{6}$ and cooling the inner conductor with water. This scheme is not the optimum design, but it does demonstrate the power hand?ing capability of realistic components.

Generating the $10 \mathrm{MW}$ of power that the transmission system can handle requires diplexing or multiplexing at least four stateof-the-art amplifiers. There are problems of phasing and load sharing with this scheme, but they are not insurmountable, and systems such as this have been used when product need was insufficient to produce new designs. However, we may well have reached the point at which there is a need for such high levels of continuous wave (cw) $r f$ power and new tubes should be developed.

With the exception of cooling and protection of high power systems (tubes in particular), other components are well developed and present no problems for rf design engineers. Cooling and protection, however, are serious problems when one considers that from the motor-generator (MG) set to the plasma load the system efficiency will be about $40 \%$. This means that for a $100-\mathrm{MW}$ system, the power dissipated as heat in the system will be $150 \mathrm{MW}$, or $3000 \mathrm{MJ}$ of energy, for a 20-s pulse. Somehow we must improve system efficiencies. In the area of generator protection, abnormally fast shutdown of equipment, such as tube faults, will have to be kept to a minimum since there will be almost zero impedance between the power source (fusion reactor) and the load (fusion heater).

Consider the LHRF case for a near-reactorsize machine. Current drive, in a high efficiency mode, may require $20 \mathrm{MW}$ of power at 
$2.5 \mathrm{GHz}$. The state of the art in klystrons is power output of $500 \mathrm{~kW}$ (development of a 1-iWW tube at $2 \mathrm{GHz}$ is under way in Japan). A typical current drive coupler will consist of stacked 8waveguide phased arrays; each guide is roughly 11 by $1.5 \mathrm{~cm}$ with a total area of $16.5 \mathrm{~cm}^{2}$. A reasonable amount of power through a guide is $6 \mathrm{~kW} / \mathrm{cm}^{2}$, so $100 \mathrm{~kW}$ per gulde or $800 \mathrm{~kW}$ per phased array is a reasonable amount of power. Thus, 25 phased arrays would be needed in this hypothetical machine. This arrangement would allow stacking five arrays at five places on the machine and, with klystron amplifiers capable of $500 \mathrm{~kW}$, would allow electronic phasing of the arrays and make tube and waveguide manufacturers very happy. To keep the vacuum interface window from looking directly at the plasma radiation, the windows will have to be placed well beyond the point where the toroidal fleld might not be strong enough to preclude electron cyclotron resonance breakdown. In addition, spectal consideracion will have to be given to the volume of the transmission system between the plasma and the vacuum wirdow.

If generators are limited to $500 \mathrm{~kW}$, the transmission systems to the rf generators will probably be standard wavegulde with water cooling. It will be advantageous to make the waveguide as large as possible to reduce losses and minimize cooling requirements. Experiments on PLT will soon be made with the $2.45-\mathrm{GHz}$ generators for current drive. This system will use round waveguides to determine what operating problems might occur from this type of feed. To be a good start-up and current drive generator, the lower hybrid system requires electronic phase shifting. Therefore, a multiplicity of klystrons is not that great a detriment, and a tube capable of 1 to $5 \mathrm{MW}$ should be adequate.

The major uses for ECRH Include plasma generation, electron ring formation, and electron bulk heating. As noted above, a need for high powers will, with present gyrotron capabilities, require far too many units. Therefore, a push is needed for higher power gyrotrons as in the present $60-\mathrm{GHz}$ development program. For the larger, higher fleld machines of the future, gyrotrons in the 100-Gkz region at $>100 \mathrm{MW}$ are needed. A near-term issue is the feastbility of windowless systems, thereby eliminating this difficult-to-build element. Quasi-optical transmission systems may be a way to avoid some problems with preserving mode purity in waveguide transmission systems. Considerabie interest has been focused on important elements such as mode convertors, filters, and polarizers, with emphasis on power handling capability and bandwidth. All of these systems (ICRH, LHRH, ECRH) will be taxed especially hard by the $\mathrm{cw}$ needs of future machines. Efficiency becomes a major issue, as does the cooling system design.

\section{RESEARCH AND DEVELOPMENT NEEDS}

In F1g. 2, three areas are blocked out for the elements of high power if generators for fusion reactors. The most difflcult problems concern the interface of the coupler and vacuum window with the radioactive plasma. This problem w1ll require close cooperation between the plasma physicists, if engineers, materials physicists, and mechanical engineers. The second most difficult block (II) is the one that will ultimately have the largest effect on the cost of reactor operation. This channel of energy includes the high power amplifier and transmission system. All efforts should be made to develop high efficiency tubes, low loss transmission lines, and matching devices that will minimize reactlve power in the transmission system. It is imperative that tube and circuit engineers work in close concert to achieve the highest efficiency possible. Taking the theoretical case of $100 \mathrm{MW}$ of ICRF power and plotting various input powers required at some range of efficiencies, we obtain the graph in Fig. 4, which points out that any funds spent for improvement here are money well spent. In the

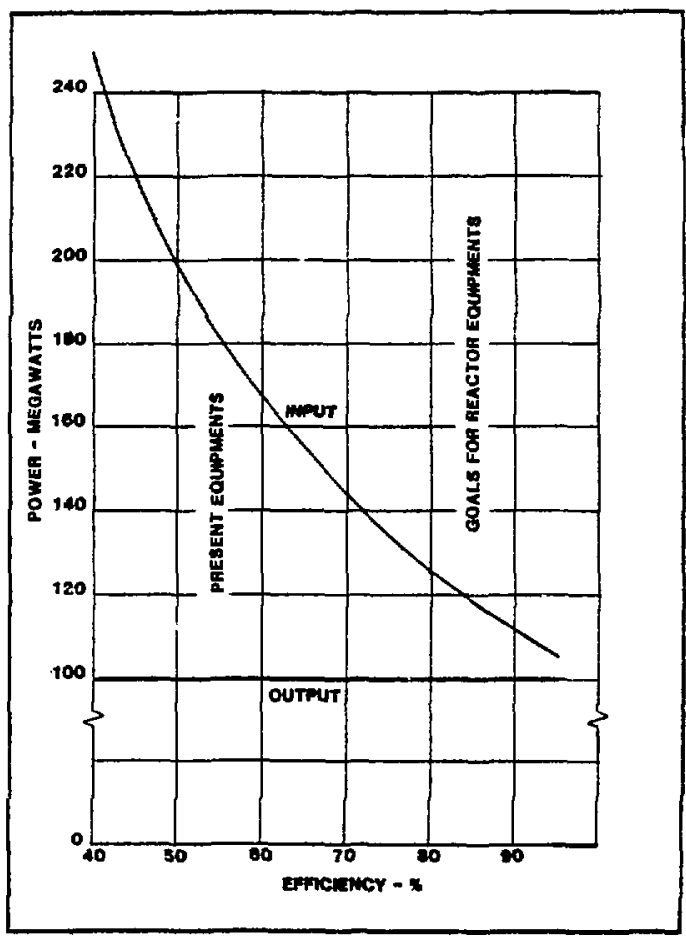

Fig. 4. I.ine power reyuired vs system efficlency for a 100-MW output. 
high frequency ICRF case, th1s means development of tubes with circuit elements inside the vacuum envelope, which might allow quasi-class $D$, high efficiency operation. It also means developing computer modeling techniques to optimize all of the components between the plasma load and the final and penultimate rf power amplifiers. Klystron manufacturers should also be encouraged to improve the efficiencies of klystrons and gyrotrons.

Block III is concerned with the development of protective devices. These devices must be developed to control fault conditions that will arise as a result of higher tube input capability and lower effective power line Impedances to the 60 -cycle source. Additional development is also required to improve the effictency of the kLystrons and gridded tubes.

Tables 2 and 3 give a broad view of the major and minor research and development efforts that will be required before there will be realistic and cost-effective use of rf energy for fusion reactors.

Table 2

MAJOR RESEARCH AND DEVELOPMENT EFFORTS

1. Transmisaion Hne fF yecuum windowe

2. Tranemiasion line de safety bresks

3. ECR and multipactor suppresaion in the evecueted portlons of transmission ithe

4. Materials tegt facility for both high power and radiation testing of system componenis

5. AF test on TFTR-1 to determine the limit on RF power dencity at the plateme surtace

Table 3

MINOR RESEARGH AND DEVELOPMENT EFFORTS

1. Development of the $1.25 \mathrm{MW}$ klystron

2. Possible development of a new super power VHF tube foe the ICRF syetem

3. Power supply components

4. RF monlturing and cuntroi systems

5. High power coaxiat shorted gtubs for water cooling ol center conductors

6. High power sfecer support for cosx

7. Theoretical anatigis of ridged waveguias

8. A comparison among coax, clrcular, and elliptical weveguide for the lower hybrid teed system

D. High power testing of coux and wevegulde componente

\section{REFERENCES}

1. E. TANNER, Project Matterhom: An Informal History, Princeton Plasma Physics Laboracory (1977; rev. 1982).

2. J. M. BERGER and E. A. FRIEMAN, "On the Pulse Method of Ionlzation and Heating of a Plasma," NYO-6043, Project Matterhorn, Princeton University (1953).

3. J. M. BERGER and W. A. NEWCOMB, "Heating of a Plasma by Magnetic Pumping," NYO-6046, Project Matterhorn, Princeton University (1954).

4. T. STIX, "Oscillations of a Cylindrical Plasma," Phys. Rev., 106, 1146 (1957).

5. J. HOSEA et a1., "High Power ICRF Heating on PLT and Extrapolation to Future Devices," in "Heating In Toroidal Plasmas, Proceedings of the 3rd Jaint VacennaGrenoble International Symposium," EUR7979EN, Commission of the Euorpean Communities (1982).

6. J. STEVENS et al., "Lower Hybrid Heating and Current Drive on PLT," in "Heating in Toroidal Plasmas, Proceedings of 3rd Joint Varenna-Grenoble International Symposium," EUR7979EN, Commission of the European Communities (1982).

7. The recent research is presented in "Heating in Toroidal Plasmas, Proceedings of the 3rd Joint Varenna-Grenoble International Symposium," EUR7979EN, Commission of the European Communities (1982).

8. R. A. DANDL et a1., Nuci. Fusion, 11, 411 (I97I).

9. R. A. DANDL et al., "Plasma Confinement and Heating in the ELMO Bumpy Torus (EBT)," in Plasma Physics and Controlied inclear Eusion Researoin (Proc. Sth Int. Conf. Tokyo, 1974) (IAEA, Vienna, i975).

10. S. BERNABEI, private communication.

11. "Preliminary Report on the Development of RF Auxiliary Heating Systems for TEPR-1," PPPL-1410, Princeton Plasma Physics Laboratory. 